\title{
Chapter 6 \\ The Politics and Culture of Climate Change: US Actors and Global Implications
}

\author{
Charles Waugh
}

\begin{abstract}
Despite the scientific consensus on global warming, many people in the USA,- - both ordinary citizens and elected leaders alike-remain skeptical of the need to act, and in fact remain skeptical of the idea that humans are contributing to global warming at all. Thus, environmental justice arguments based on United States carbon emissions and the disproportionate impact of rising temperatures and rising sea levels on tropical developing nations such as Vietnam frequently fall on deaf ears. This chapter explores the political and cultural construction of this deafness, seeking a better understanding of how and why so many Americans refuse to act to address global warming. The two main sources of this deafness that this chapter address are (1) the politics of carbon-intensive energy producers such as the coal and oil industries, demonstrating the ways in which those industries have distorted the debate over global warming, have found eager allies in political candidates willing to accept large campaign contributions, and-with the help of other industries such as automobile manufacturing and home construction-have encouraged the second main source of denial: (2) a culture of aggrandized individualism that places greater value on personal identity construction than on the national and global common good. Once these sources are established, the chapter recommends strategies for using narrative to overcome cultural and political resistance to climate change mitigation that may be effective not only in the United States, but in Vietnam as well.
\end{abstract}

Keywords Climate change $\bullet$ Culture $\bullet$ Individualism $\bullet$ Narrative

Since the election of Barack Obama in the United States, much has been made by the American news media of the new green economy, with the president himself calling for an investment in renewable energy and climate change mitigation strategies that he believes will have the twofold effect of resuscitating the American

\footnotetext{
C. Waugh $(\bowtie)$

Department of English, Utah State University, Logan, Utah, 84322-3200, USA

e-mail: charles.waugh@usu.edu
} 
economy and preparing the nation for a hotter world. But so far, the overall impact of many of these strategies has fallen short of their goals. For example, one plan, the Consumer Assistance to Recycle and Save Act of 2009 (better known by its nickname "Cash for Clunkers"), sought to reduce carbon emissions and to revitalize automobile sales by encouraging owners of inefficient and highly polluting vehicles to trade them in for newer, more efficient, and less polluting models. The government subsidized the program by supplying the money to buy the old vehicles in order to ensure they would be taken off the road and destroyed. Americans traded in nearly 680,000 cars and trucks for more efficient replacements, saving an annual average of \$32,947,886 in fuel, and preventing an estimated 379,000 metric tons of $\mathrm{CO}_{2}$ from being released annually (US Department of Transportation 2009). While any reduction of $\mathrm{CO}_{2}$ emissions is a good thing, at just $0.15 \%$ of the United States' annual carbon emissions, such results fail to be inspiring, and in fact, raise the question of why more people did not take advantage of the program. After all, 680,000 may initially seem like a lot of cars, but it represents just $0.27 \%$ of the total number of registered vehicles in the United States, or the participation of just $0.22 \%$ of the US population.

Setting aside the economic reasons for not participating, from figures such as the United States' total annual carbon emissions as reported by the United Nations' Millennium Development Goals Indicators, we know that the United States is the second largest $\mathrm{CO}_{2}$ emitter in the world, and for a long time was the number one emitter. As individuals, Americans live a more carbon-intensive lifestyle than all but a few nationalities (UN Statistics 2010). Why did not more of them take advantage of a program that would not only benefit themselves, but also help reduce this enormous carbon footprint?

The full response to that question has many complicated parts, and this chapter addresses several of them, but the short answer is that many people in the United States-both ordinary citizens and elected leaders alike-remain skeptical of core climate change assumptions. Some look at their local weather and refuse to believe the Earth is warming in any significantly different way than in other decades-long trends, and some, when they finally do confront the overwhelming data that the Earth is indeed growing warmer, quickly attribute that warming to the Earth's natural long-term cycles of warming and cooling, and in effect deny that human activity has anything to do with it. In both scenarios, these skeptics implicitly claim that nothing humans can do will make any difference. But if humans want to continue to enjoy an earth that still resembles the earth that we all know now, and if we wish to avert the catastrophic loss of life, society and capital that unchecked greenhouse gas emissions will cause, we must find a way to break through enough skepticism to make a difference. This chapter first analyzes American climate change skepticism to find its political and cultural origins, and then suggest ways to reframe or repurpose those origins to inspire people to act.

It might be easier to understand US climate change skepticism if seen through an example. In 2010 in the state where I live, Utah, the conservative state legislature responded to the US Environmental Protection Agency's "carbon reduction policies" by passing House Joint Resolution 12, which "urges the United States 
Environmental Protection Agency to immediately halt its carbon dioxide reduction policies and programs and withdraw its 'Endangerment Finding' and related regulations until a full and independent investigation of the climate data conspiracy and global warming science can be substantiated" (Utah 2010). It follows with a litany of unsubstantiated reasons why climate change science is flawed or otherwise cannot be trusted, how climate change action will cost governments and tax payers billions of dollars that will simply line the pockets of climate change researchers, prevent the use of millions of acres of agricultural land, starve the people now eating food produced on that land, and "ultimately lock billions of human beings into long-term poverty" (Utah 2010). The paranoid hyperbole the bill expresses arises in part as a response to recent revelations that climate scientists altered findings to create a sense of urgency in the public, but it is also representative of the way many Utahns (though not all, obviously!) and many Americans feel about climate change. Letters to the editor published in my local newspaper often "debate" climate change, with typical entries often sounding like this one: "[Climate change science] is purely unadulterated 'horse puckey.' These clowns are in it for the money at yours and my tax money expense [sic].... With the recent revealing reports of false documents of global warming, Al Gore and his pals should be 'cut off' from our taxpayers' funding....Climate change is a scam at our expense. Believe it. You farout loons are crazy" (Larsen 2010).

Neither the writer of this letter nor the sponsor of House Joint Resolution 12 is a scientist, nor are they apparently consumers of information from leading scholarly or even popular science journals or even mainstream media. So where do they get such strong feelings about climate change, and why would they believe climate change mitigation strategies are just some farfetched and elaborate conspiracy to steal their money?

One part of the answer is political: As early as 1998, the biggest energy producers in the United States, corporations such as Exxon, Shell, and BP, along with organizations that they support such as the American Petroleum Institute and the Cato Institute, began a systematic campaign designed precisely to create public skepticism on global warming. Taking the offensive on what they believed would be a downturn in demand for their products, or a tax on the carbon their products released, they began to funnel huge sums of money to organizations and scientists who would provide research to support the contentions that global warming did not exist and that human activity could not be definitively linked to climate change. Exxon alone ultimately paid more than $\$ 16$ million between 1998 and 2004 to 40 different groups, who in turn paid researchers to produce reports to support their claims. Perhaps the most cynical part is that the oil corporations never had any intention of ever proving the validity of their paid scientists' work. In a memo leaked to the New York Times, the American Petroleum Institute declared that their campaign would be successful just by creating the appearance of doubt about climate change science. They knew as long as the media presented the issue of climate change as a debate, at least some of the public would believe the science was inconclusive and there would be no real motivation to limit fossil fuel exploitation or use. Since then, Exxon has claimed to "soften its stance" on global warming, and yet 
they have continued to support climate denial institutes with millions of dollars every year since making that claim (Union of Concerned Scientists 2007). ${ }^{1}$

The energy corporations have also made large donations to political campaigns, giving candidates sympathetic to energy exploration and development vast sums to spend during elections. Since 1990, oil and gas companies have contributed more than \$238.7 million to federal level campaigns, with $75 \%$ going to Republicans (Center for Responsive Politics 2010a, b). Candidates claim campaign donations do not necessarily mean they do whatever the donors tell them to. But in practice, it seems this is often the case. ${ }^{2}$ For example, in January 2010, the Alton Coal Development company made a $\$ 10,000$ contribution to the reelection campaign of the energy sector-friendly governor of Utah, Gary Herbert. That same day, at the governor's request, Alton's application to open a mine in an environmentally sensitive area was fast-tracked for approval. When pressed, the governor claimed the two incidents were unrelated, and as long as no record exists of his asking for the money or the coal company asking for his help with the approval process, corruption like this goes unpunished (Foy 2010).

In the case of the George W. Bush administration, scores of energy sector personnel moved into the government itself. Both President Bush and Vice President Cheney had been energy corporation executives, and as they filled positions within their administration, they relied heavily on former industry lobbyists, lawyers, managers, and board members. For example, the chief of staff for the White House Council on Environmental Quality from 2001 to 2005 was Philip Cooney, who had spent the previous decade as a lawyer for the American Petroleum Institute. As CEQ Chief of Staff, Cooney was able to act as a filter for all environmental information distributed by the federal government, at times changing or deleting parts of reports that contained data or predictions contrary to industry opinion. When US government scientists in the Climate Change Science Program submitted their 2002 Strategic Plan, Cooney made 650 changes, removing estimations of threats such as reductions in glacial ice and available melt water, and adding qualifying words to projected outcomes and impacts to make them seem less likely. Another tactic used by the Bush administration to thwart the dissemination of science contrary to their energy-intensive political goals included requiring scientists nominated for advisory boards to pass interviews that tested them not for their expertise but for their political allegiance (Shulman 2006, pp. 117-123).

\footnotetext{
${ }^{1}$ The climate change denial actions of ExxonMobil and the institutes it supports are well documented. For example, see Cushman (1998) and Harkinson (2009).

${ }^{2}$ A prominent example at the federal level comes from James Inhofe, Republican Senator from Oklahoma and the most vocal skeptic of global warming in the Senate, who received $\$ 432,950$ between 2005 and 2010 in campaign contributions from the oil and gas industry, \$206,654 from electric utility political action committees, and \$176,983 from lobbyists. It is hard not to imagine that he is not saying what the energy industries want him to say. Figures from Open Secrets.org, the Web site of the Center for Responsive Politics. Retrieved from http://www.opensecrets.org/ politicians/summary.php?cid=N00005582\&cycle $=$ Career
} 
And while the Bush administration is an extreme case of oil industry influence over US policy and opinions, that influence did not appear over night. Rather, as Naomi Oreskes and Erik Conway have convincingly shown (2010), it is the culmination of a long, concerted effort by conservatives to shift policy discussions away from scientific facts and the common, global good toward short-term economic interests. Following the lead of economists such as Thomas Schelling and William Nordhaus, whose reports on climate change in the early 1980s discounted the science and leading scientists' predictions of environmental disaster in favor of economic uncertainty and a "wait-and-see" attitude, groups such as the Marshall Institute have been churning out "information" about global warming that has never withstood scientific scrutiny and whose purpose is simply to cloud the issues and to encourage more delay and inaction (Oreskes and Conway 2010, pp. 177-180). One such Marshall Institute report, Global Warming: What Does the Science Tell Us? (Jastrow et al. 1989), employed tactics such as presenting only the data that supported their conclusions and misrepresenting peer-reviewed research to make the report look like a credible refutation of climate change science. Because the report came from a policy think tank, it had never been peer reviewed, but because it appeared to use real scientific data (albeit in an incorrect way), many policy makers were duped. Similarly, releasing such reports to the public through conservative media outlets such as the Wall Street Journal has allowed climate change deniers to distribute their ideas widely, but when leading scientists have written letters to the editor of the Journal to refute the science, the newspaper has either refused to print the rebuttals or edited them heavily to reduce their impact. Journals such as Science and Nature have eventually published full rebuttals, but to much smaller readerships and with the damage already done (Oreskes and Conway 2010, pp. 209-213).

What the Marshall Institute and the energy industries they serve have always realized is that what they write are policy suggestions, and that their audience is composed of policy makers. They are not scientists and they are not writing scientific articles that aim to have their science compete in the realm of science with other scientific claims. Instead, they have exploited the less rigorous standards of mainstream publishing to make their claims and have provided policy arguments and supporting materials to like-minded policy makers that say that the science is not the main thing to consider when it comes to climate change. And their story appeals to so many people in part because it preserves the status quo-no one has to do anything different in their version of the future-but in even larger measure because they often package these policy suggestions to take advantage of powerful elements in American culture.

Given such an overwhelming effort to mislead the public, it is no wonder that ordinary citizens such as my letter writing neighbor are convinced that global warming is not what the scientists say it is. In fact, the effort to deceive Americans about climate change has been so monumental; it would be easy simply to blame the politicians and the corporations for the denial of climate science and the perpetuation of a carbon-intensive way of life. But the situation is more complicated than that; in fact, it goes to the very core of American cultural identity. After all, 
what those corrupt corporations and politicians are really defending is the uninhibited freedom for individuals to emit as much carbon as they can personally afford, to buy as many things and to use as much energy as they can pay for. (It is no coincidence that several of the climate change denial groups funded by Exxon have names like the Frontiers of Freedom Institute and the Free Enterprise Institute). And as selfish as that sounds, it is a privilege that resonates with vast numbers of Americans. Of course, the corporations are still intimately involved, since they are selling what the American people are buying, but a deep complicity runs between the average American citizen and the corporations that sell them the things they want.

A good way to see this complicity comes from the automobile industry, which by nature involves both a carbon-intensive production process and product. Since the establishment of fuel efficiency standards in the United States in 1975, the American automobile industry has argued consistently for the more lenient standards that have allowed them to cater to base consumer demands: more passenger and cargo space, more powerful engines, and more luxurious interiors. At the same time, these more lenient standards have allowed them to focus less on efficiency, and more on the idea that a car is not just a car, but an extension of the owner's personality. A recent BMW commercial aired in the United States demonstrates this idea quite clearly. The commercial depicts beautiful cars being driven by people with big smiles on their faces, and the narrator says, "We realized a long time ago, that what you make people feel is just as important as what you make, and at BMW, we make joy" (BMW 2010). In the United States, big trucks are sold on the idea they make the owner tougher, more rugged. Minivans are sold by suggesting that parents are better parents if they buy the van that keeps their children safer, or now, better entertained. The car's efficiency is usually treated as an afterthought, even in ads for the most efficient cars. For example, commercials for the popular brand of hybrid electric and gas car, the Toyota Prius, mainly pitch a certain kind of way of being in the world, a personality that makes the world a happier place to live in.

In their "Harmony" TV commercial, Prius promises the buyer "more power and more space," two of the things many Americans want in their car, and that "the world gets fewer smog forming emissions." But the pitch for the environment is understated in comparison to the ad's music and visual effects. The song in the background is Loretta Lynn's, "Let Your Love Flow," and as we watch the Prius drive along a highway, the landscape is transformed from a bland white to a vibrant green and blue made up of smiling children in blossoming plant costumes. Presumably because in the United States so many people are still in denial about global warming, the ad does not even mention the reduction in carbon emissions, suggesting instead the reduction in smog (Toyota 2010). Apparently, the important thing to take away from the ad is, as BMW put it, how it makes you feel. But this sort of identity construction at least is relatively benign in comparison to what happens in Ford's "Built Ford Tough" commercials. In hundreds of different ads, various aspects of their trucks' designs are touted as being tougher than their competition, with the implication always being, as one ad asks the viewer directly at the end, "Are you tough enough?" (Ford 2007). In other words, the overdesign of 
the truck, adding weight and losing efficiency, is justified by a consumer who also wants to be seen as stronger and more capable of physical work than anyone else.

One way to explain this emphasis on individual identity construction, as well as the toughness message from Ford, comes from the United States' frontier history, whose mythology has been perpetuated by popular culture since the late eighteenth century. In brief, these stories feature individuals who go out into the wilderness with just the right tools and supplies and turn that wilderness into civilization. These are the stories of early explorers like Daniel Boone and Davy Crockett, but also of western cowboys like Wyatt Earp and Wild Bill Hickok who are portrayed as individuals who struggled heroically to tame the frontier. Of course the legends around these historical figures have exaggerated their accomplishments, and like all myths, some things are emphasized over others. It does not matter that Earp had brothers and friends, or that Crockett had a wife and children and neighbors helping him, the myth reinforces that these men as self-reliant individuals played an enormous role in making the United States what it is today.

American studies scholars have rigorously debated the origins and mythic quality of this rugged American individualism, and not all of that scholarship can be revisited here, but one common explanation suggests that, despite the truly interdependent nature of early American life, "throughout the Revolutionary period and beyond, most Americans made their livings in agriculturally-based hamlets, or in free-standing farmer's homesteads of one or a few families. These material circumstances seem likely to have encouraged a clear sense of economic self-reliance or independence in much of the population, which, in turn, may have eventually promoted a generally more individualistic outlook among many settlers" (Grabb et al. 1999, p. 527). This emphasis on economic self-reliance runs through a great deal of American thought, even through the writing of the United States' greatest champions of the environment such as Ralph Waldo Emerson, Henry David Thoreau, and Wendell Berry, though they each in their own way also accompanied their celebration of independence with warnings not to become "the tools of their tools" (Thoreau 1854, p.132). A second explanation for American individualism comes from what political scientist Barry Shain calls a conflation of "local communal hostility toward the provincial or the imperial (later national) center...with a common 20th century hostility toward all authority" (Shain, 1994, p. 86). ${ }^{3}$ Combining these two explanations gives us a competent portrait of the consumer that Ford truck commercials are trying to reach: Someone who earns his living by himself, with his hands, and who does not like being told what to do by anyone, and if not that person, someone who fantasizes about being him. In short, my letter writing neighbor.

\footnotetext{
${ }^{3}$ Such feelings are not exclusively American; many cultures and peoples feel similarly, even in Vietnam, where the saying goes, Phép vua thua lẹ làng (the emperor's law yields to village custom). But unlike in Vietnam, where there is also a saying, Biết thì thua thốt, không biết thì dưa cột mà nghe (if you know, speak up, if not lean against a pillar and listen), America's infatuation with individualism has led many to believe that all opinions have equal value.
} 
The values this myth and these advertisements perpetuate are precisely the ones he expressed in his letter to my local paper quoted above. The value of rugged economic self-reliance and distrust of outside authority combine to express the fear that government agencies, scientists, and representatives are using climate change as a way to tell him what to do and to take his money. The nexus of corporations, politicians, and conservative media make the situation worse by presenting irrational opinions about individual rights and misleading pseudoscientific information as rational counterarguments to the scientific certainty of global warming, but to an extent, they are successful because they play on a distrust of authority that has been enshrined in a culture and history that many Americans believe began with the Declaration of Independence. At the same time, Americans are inundated with corporate messages to indulge their sense of individual importance, to enjoy what they think they have earned, and ignore requests made for the common, global good.

Because the only information some Americans get is what they hear on politically motivated radio and television programs, these citizens never fully confront the legitimacy of climate change science. But even if these Americans did engage with clearly articulated, sound scientific proof of climate change, their feelings of skepticism and distrust, and ultimately the fear of losing their privileged access to an overabundance of material goods would most likely prevent them from being convinced to do anything. Climate scholar Mike Hulme has applied planning theorist Horst Rittel's term "wicked problem" to these entrenched rejections of climate change science because they so intractably defy reasonable problem-solving strategies. But Hulme refuses to give up on the idea that it will take everyone in the world, especially climate change skeptics, to change our world for the better. Coincidentally, his answer to this "wicked problem" employs the exact same methods of myth-making, identity construction, and even a distrust of authoritative solutions that helped make the problem so intractable to begin with.

Hulme's book, Why We Disagree About Climate Change (2009), explores the many ways that people around the world perceive climate change, explaining how different values, beliefs, and forms of government combine to make "solving" climate change as a problem impossible. Because "solving" climate change involves "uncertainty; inconsistent and ill-defined needs, preferences and values; unclear understanding of the means, consequences or cumulative impacts of collective actions; and fluid participation in which multiple, partisan participants vary in the amount of resources they invest" (Carley and Christie 2001, p. 156), no authoritative, top-down solution will ever satisfy everyone, even if one could be devised. Instead, Hulme argues, "we need to approach climate change as an imaginative idea, an idea that we develop and employ to fulfill a variety of tasks for us" (p. 329).

Treating climate change as a source of inspiration frees us to go more directly to the forms of identity construction that will allow us to find common ground and take action that will help us all. As the Alliance of Religions and Conservation suggests, "Without...[narrative, myth, and metaphor], policies will have very few real roots.... Without narrative, few people are ever moved to change or adapt" (Alliance 2007), and Hulme agrees: "In a world where the globalizing powers of capital, trade 
and consumption separate us from the local stories that give meaning not just to climate, but also frequently to our lives, this [strategy] also offers a way of reconnecting ourselves with climate through the telling of stories" (p. 356). In other words, to mobilize the world to act on climate change, we have to "inspire," not to "convince." We have to construct stories about ourselves and climate that allow us to better examine who we are, who we want to be, and what we want from life.

Such a strategy seems especially well suited to American climate change skepticism. It allows us to build from our mythic past when we struggled to make a better life out of an unpredictable wilderness. It allows us to turn that distrust of authoritative, top-down decision-making into individualistic, everyday solutions that still allow for a high quality of life. And it allows us to construct narratives that connect the values of the past with the choices we must make in the present. As Hulme suggests, "We can use the idea of global climate change to tell ourselves new stories about ... the consequences of our collective behaviours. We can use the idea of climate change to move beyond the separated categories of the physical and the cultural, beyond the framing of climate change that uses the language of problem and solution" (p. 357). Thus, we must express the idea of climate change in stories that can inspire the world, one individual at a time, to create a new way of understanding the choices we make and how they affect people who live far away from us.

Based on his analysis of the arguments that have obstructed climate change mitigation strategies in the past, Hulme proposes a taxonomy of four myths that represent four human impulses or emotions as a way of understanding how stories we tell about climate change might motivate us: (1) Eden, which arises out of our sense of nostalgia, (2) Apocalypse, which arises from our fears for the future, (3) Babel, which expresses our pride for our sense of mastery and control over the environment and other human beings, and (4) Jubilee, which engages with our sense of justice, of doing the right thing by others affected more dramatically by climate change (p. 358). But in order to know what will motivate a particular group best-as scholars of rhetoric and narrative from Aristotle to Kenneth Burke, Wayne Booth and others have shown - we first have to know something about the audience. A story can only do the work Hulme suggests when you know which story to tell.

For example, the climate story an individual American might tell another individual American, over the phone, between father and son or sisters or close friends, will be different from the story told by director Roland Emmerich to the American mainstream public in the climate change thriller The Day After Tomorrow. The story I would tell to my Vietnamese colleagues while working in Vietnam might not be the same story I would tell my neighbor when chatting about our gardens and the weather. And even within the larger community of climate change skeptics, the story I might tell to inspire the writer of the letter to my local newspaper would not necessarily be the story I would tell to Jeff Kueter, president of the Marshall Institute.

So what would it take to inspire a skeptic like my letter writing neighbor? As Shain and Grabb have suggested above, and as the American Tea Party movement has confirmed, the idea of America that comes from its revolutionary period is very 
much alive in the contemporary mainstream United States. The sense of individualism, of disliking being told what to do by some far off distant ruler, of this irascibility somehow defining a quintessential American spirit are all common features not only of Ford truck commercials but also of contemporary conservative discourse. An extreme variant, the Appleseed movement, goes one step further by connecting those same characteristics to the type of marksmanship conjured up by recollections of minute men militia. When pressed to explain why every American should own an AR-15 rifle and know how to shoot it, Appleseed founder Jack Dailey expressed the sentiment common to all these groups: "Because they [unspecified antecedent, suggesting anyone] want to tell us what to do. And we don't want them to tell us what to do" (Schwartz 2010, p. 41). Here, Hulme's use of four myths can really help make clear what is going on. Fear for the future, combined with pride for the mastery over nature and other human beings and a sense of justice, have all been wrapped together with nostalgia for a time when problems could be solved by shooting at them. But it is the nostalgia that is the most important part. When a Tea Partier reaches for that tricorne hat, or an Appleseeder reaches for a gun, he or she is reaching for the past.

T. Boone Pickens, the oil tycoon turned wind farm proponent, does the same in his attempts to convince conservatives of the need to turn away from imported oil. Consider the rhetoric from his Web site for the Pickens Plan: "Lend your voice to the call for American energy independence....We are organizing the New Energy Army in every Congressional District" (Pickens 2010). This is not about reducing our carbon footprint-it is a revolutionary call to arms!

But there is more from the American Revolution than just guns and independence that will resonate with Americans today. Stories of imperial imposition were commonplace in late eighteenth century colonial America, stories that told of unfair taxes yes, but also local stories of being taken advantage of by someone far away, stories of the inherent injustice in a colonial system that featured a distant king telling people what to do with the land they lived on. These stories involved real people who were forced to quarter soldiers in their homes, real people whose access to their local forests and its resources was limited by the Broad Arrow policy, real people whose potential was limited by the Royal Proclamation of 1763 barring them from westward migration. ${ }^{4}$ The Revolution was the means through which they expressed their independent spirits, refused to be hobbled any longer, sacrificed their time and revenue, and rose to their full potential.

Stories that equate corporate greed, excess, and callousness with imperial rule can be marshaled in the same way, and have been already, perhaps most notably in the case of BP's former American CEO Tony Hayward's yachting vacation during the massive 2010 oil spill in the Gulf of Mexico. The same could be said for the public outcry in 2008 when gasoline prices went through the roof while the oil companies posted record profits and their CEOs raked in outrageous salaries and benefits.

${ }^{4}$ For examples of these stories, see Roberts (2010) and Calloway (2006). 
But even these have not been enough to inspire my letter writing neighbors to give up their big trucks, ATVs, and snowmobiles. What else can be done? According to Hulme, it is "the local stories that give meaning not just to climate, but also frequently to our lives" (p. 358) that need to be told, so perhaps the stories my neighbors need to hear are the ones from local scientists predicting what climate change will mean for folks right here in my little mountain valley. Will climate change mean less snowfall? Will less snowfall mean fewer opportunities for skiing and snowmobiling? Will less meltwater mean the end of agriculture in our valley? Will droughts leave our forests more susceptible to mountain pine beetles and eventually wipe them out? Stories like these-intertwined with stories of family outings, camping and fishing and hunting stories, stories of local adventuremay finally touch the things my neighbors care about, help them imagine how their own lives will change in a warmer world, and make them nostalgic for the important role climate plays in the places and activities they hold dear. Motivating them to do something might then rely on appeals to the injustice of corporate indifference to climate, to their own frontier spirit, or to doing something locally before the federal government imposes a solution from outside. But the rub will always be to get their attention first with something that already interests them, and the more local the origin of the story, the science, the activities, and the impacts, so much the better.

Of course, this is not how new science tends to be disseminated. Instead, the bigger the news, the more important the national journal it comes out in. And most scientists probably do not want to spend all their time writing different versions of their work for different audiences. In these cases, perhaps collaboration with writers from various locations likely to be impacted by what the scientists have found would help get the job of adapting their work to local audiences done. Greater partnerships between scientists doing cutting-edge climate research and local writers who can publish in the types of newspapers, magazines, and Web sites that skeptics already read stand a much better chance of inspiring the presently uninspired than even the best-written article in top journals like Science and Nature.

But not everyone in the United States who still remains somewhat skeptical of climate change science need so much frontier, Daniel Boone-type inspiration. Many others, still less than literate in science, still unsure what to make of the conflicting claims, but with good hearts can be inspired by stories arousing their compassion and sense of justice. Moderately conservative "soccer moms" and dads around the country have already shown how issues that concern the health of their children can bring them to support environmental legislation and more climate friendly local and organic agriculture. Stories about their children's relationship with climate in the future could be effective, but so too could stories about the suffering of others. As writers such as Donald Brown have argued, ethical arguments about climate change need to be made more prominently in the United States (Brown 2010), and this group in particular seems likely to be a receptive audience to stories about the unequal distribution of negative effects of climate change and how children in other places around the world will have to bear a much greater burden than their own. 
The clarity of this injustice will not be lost on such an audience. The biggest carbon emitters have well-developed economies and mainly occupy temperate zones with greater elevations that will allow them to better weather negative impacts. Meanwhile, developing countries like Vietnam that have small carbon footprints, tropical climates, and low-lying coastal geography are predicted by the World Bank to suffer the worst of the consequences (Dasgupta et al. 2007). Put succinctly, Vietnam and countries like it are being forced to pay the true cost of the United States' culture of consumption. With a compassionate audience, a story about the loss of ancestral lands, cultural customs, or displacement can resonate and make a difference, as long as it is centered around people and life experience, not just a vehicle for the science of sea level rise. This is the type of audience who can hear arguments about the injustice of the United States' carbon culture and how the overconsumption of goods and energy in the United States causes devastation in other parts of the world and be inspired to act. But because these stories have to some extent already begun to be told, perhaps the problem is less of content and audience but of distribution, and the solution may again lie with the need for help from more local writers, with more of these stories in local publications linking the rest of the world to even the smallest communities in the United States.

And while the focus of this chapter so far has been on the political and cultural origins of US climate change skepticism and the kinds of narratives that might inspire those skeptics into action, it is important to recognize that this process of adapting global science to local audiences must occur everywhere in the world, using narrative to link each and every locality to the political, cultural, and individual choices that impact and will be impacted by climate change, because the story of the injustice of climate change does not simply end with lifestyles in rich nations causing a disproportionate amount of climate affects in developing nations. In fact, it has a historical dimension and a contemporary quality of life dimension that makes the story even more complicated. The culture of consumption ${ }^{5}$ and aggrandized individualism that has made the United States the leading carbon producer for decades has now become a global phenomenon, and the carbon emissions for developing nations have begun to rise, most dramatically in China, whose recent exponential growth in manufacturing and electricity production and consumption has brought it to the top of the list of yearly emissions, but also in Vietnam, whose carbon emissions increased by more than 300\% between 1995 and 2005 (CAIT 2010). China's climate change ambassador Yu Qingtai has made strong arguments for considering the historical record of $\mathrm{CO}_{2}$ emissions as the basis for future emissions reductions, arguments that attempt to reconcile the injustice of the West's carbon-intensive colonial period with the victims of that period's need to emit carbon to catch up with the West's infrastructure and standard of living (Vaughan 2009). But while this makes perfect sense historically and in terms of righting a wrong from the imperial past, to say that developing nations should emit as much

${ }^{5}$ For an historical analysis of how Americans came to associate the accumulation of material things with status and personal identity, see, for example, Cohen (2003). 
carbon as have the developed nations does not make a lot of sense for the planet. What is needed is green development, development that gets the same social and economic results but without emitting the same amount of greenhouse gases.

Unfortunately, recent changes in Vietnam's Mekong Delta do not appear to be the kind of development that ultimately will be sustainable. The Intergovernmental Panel on Climate Change has predicted a 1-3 m rise in sea levels over this next century, which means that a significant portion of Vietnam's arable land will be submerged. With just a $1 \mathrm{~m}$ rise, $5 \%$ of Vietnam will be under water, and with the IPCC's worst-case scenario, a $5 \mathrm{~m}$ rise, $16 \%$ of Vietnam disappears beneath the waves. In all cases, the areas hit first and worst are the fertile river deltas where much of the nation's crops are grown, and where most of the people live. In the $5 \mathrm{~m}$ scenario, nearly $40 \%$ of the population-over 34 million people-will be displaced (Cruz et al. 2007). This is why the World Bank has predicted that Vietnam will be one of the five countries most impacted by climate change, with the world's worst impacts in lost GDP, population displacement, and urban areas destroyed (Dasgupta et al. 2007). And yet, despite these dire warnings, many Vietnamese are rushing headlong toward a far greater carbon-intensive way of life.

One of the ways Vietnam has traditionally managed to keep a low carbon profile is local, sustainable production of food. For millennia, crops were grown for local consumption, rice paddy was rotated with mung beans and other fallow crops for nitrogen fixing, and grazed by buffalo and ducks for fertilizer. But now most of the rice grown in Vietnam is done so for export with the aid of chemical fertilizers, and the rice preferred by the Vietnamese to eat comes from Thailand (Vietnam News 2010). Many farmers in the Mekong Delta have given up traditional farming altogether, and have turned to raising shrimp because it is perceived to be the only way to get ahead financially. But whether such entrepreneurs can actually get ahead is uncertain, and converting a farm from traditional, sustainable agriculture to shrimp aquaculture suddenly turns formerly carbon neutral land into one of the many cogs in a global greenhouse gas making machine.

Mr. Bich, a shrimp farmer in the Mekong Delta's Vinh Chau District, explained his experience making this transition. An international shrimp food producer gave him the loans to have his paddy excavated for shrimp ponds and to buy his initial stock of fry, the necessary equipment such as feeders and water agitators, and shrimp food. The food, which he had to sign a long-term contract for, comes from "trash fish" harvested from fisheries off the Pacific coast of South America. Since Mr. Bich converted all his land to shrimp production, the earnings he makes from the shrimp now have to provide enough to pay back the loan and continue to buy the contract's worth of shrimp food, plus all his other costs of living including the food he and his family eat, which may now come from as far away as Thailand, China, or even the United States. The land has been stripped of vegetation to increase the temperature of the ponds, which is good for producing shrimp, but not so good for keeping the house cool, preventing erosion, or growing fruits or vegetables for family consumption. Maybe if Mr. Bich were the only one who has done this, the impact would be minimal, but of course he is not alone. With the encouragement of both the provincial as well as the national government, many Vietnamese 
farmers have converted their farms completely to aquaculture-up to $98 \%$ of all farmers in some Mekong Delta districts (Ngo 2010).

When asked why he decided to switch to aquaculture, unsurprisingly Mr. Bich answered that he had heard a story about someone else in his district who had made a fortune that way. Here too narratives are playing an important role. But what other narratives, what "local stories that give meaning not just to climate, but also frequently to our lives" might be told in the Mekong Delta to raise awareness of impending climate changes and consequences?

Of course, the Vietnamese will know the best answers to this question. As an outside observer of Vietnamese culture, though, some possibilities come to mind. Ho Chi Minh's famous remark, "Không có gì quý hơn độc lập, tự do," (Nothing is more precious than independence and freedom) can be found on posters in public spaces throughout Vietnam. Stories that highlight sustainable agriculture could certainly draw on this sentiment, especially in contrast to the situation of having to follow the dictates of contracts with foreign companies to which one is perpetually in debt.

More generally, care for the environment can frequently be found in Vietnamese folk literature. Stories from folk tradition can do the same kind of work that myths of origination do to tap into deeply held and often unquestioned beliefs, feelings, and motivations. For example, most Vietnamese will already know the story of Chu Cuoi, the boy in the moon. In brief, the story involves a boy who finds a magic tree whose leaves heal all wounds and illnesses. He knows he must care for the tree diligently, and that as long as he does so, it will provide for him, but when he finally does allow it to be mistreated or neglected, the tree pulls up its roots and begins to rise into the sky. The boy quickly latches on, trying to weigh it down. But the tree continues upward, stranding the boy in the moon, where he sits to this day, playing his flute and pining for his terrestrial home. Different versions of the story change some of the details, but the essence of the story is always the same: the boy has an obligation to the tree and there are sad consequences when that obligation is not met.

To better highlight positive, proactive behavior, one might harness the story of Mr. Thirty, a tiger who takes care of an old woman after killing her son. In her grief, the woman roams the forest until she finds the tiger and then scolds him for preventing her son from caring for her in old age, shaming him deeply. The tiger begins to make up for her loss by delivering wild game to her door, and supports her for the rest of her life. Even after her death, the tiger continues to bring an offering of food to her grave on the thirtieth day of each lunar month. The story reminds us of the dangers the environment holds, as well as its ability to care for us when we act dutifully and with respect. It is also a story about obligations and the need to think about the larger ramifications of our actions.

But as before, every audience will be different, and so these stories may or may not resonate. For young, urban Vietnamese, perhaps the stories they most need to hear are ones that take what they may already know-climate change is real and will have huge negative impacts on Vietnam-with what they may not put together-that the endless pursuit and accumulation of material things such as the 
latest, most fashionable motorbike, car, or cell phone, when multiplied around the globe makes climate change's worst-case scenarios all the more likely. Vietnamese youth are also great candidates for telling stories of their own, for connecting with the rest of the world and making people in the industrial West understand how their lifestyles affect one another.

Telling stories about climate change that intertwine the deepest roots of our cultures with real people making real decisions in the world today can help us achieve what Hulme suggests:

\begin{abstract}
We should use climate change both as a magnifying glass and as a mirror. As a magnifier, climate change allows us to conduct examinations-both more forensic and more honest than we have been used to - of each of our human projects: whether they be of projects of personal well-being, self-determination, liberated or localized trade, poverty reduction, community building, demographic management, or social and psychological health. Climate change demands that we focus on the long-term implications of short-term choices, that we recognize the global reach of our actions, and that we are alert both to material realities and to cultural values. And as a mirror, climate change teaches us to attend more closely to what we really want to achieve for ourselves and for humanity. (pp. 362-363)
\end{abstract}

Stories can connect us with our past and inspire us to make good decisions for the future, all while providing a better understanding of the global dimensions of our actions in the present. Whether inspiring climate skeptics in the United States to act for the greater good, or helping farmers in Vietnam to imagine other ways to lift themselves out of poverty, scientists must become storytellers too, or enlist the help of local storytellers to adapt facts and predictions to plots and narrative, to give the science flesh and bone and heart.

Neither Hulme nor I mean to suggest that narrative alone can help us address global climate change. Only through science can we begin to know the full range of physical effects a warmer world will create. But as the interdisciplinary nature of this volume demonstrates, it will take approaching climate change from every conceivable intellectual direction to know what climate change will mean, and it will take stories that reflect each of our own cultures' values and aspirations to inspire the world, one individual at a time, to act.

\title{
References
}

Alliance of Religions and Conservation (2007 Dec 7) ARC/UNDP programme statement on climate change. Retrieved from http://www.arcworld.org/news.asp?pageID=207

BMW (2010) Joy commercial. Retrieved from http://www.youtube.com/watch?v=ji1rDlt4m60

Brown D (2010) Are ethical arguments for climate change action weaker than self-interest based arguments? why taking ethical arguments off the table is like a soccer team unilaterally taking the goalie out of the net. Penn State Rock Ethics Institute Climate Ethics. Retrieved from http://rockblogs.psu.edu/climate/2010/08/are-ethical-arguments-for-climate-change-actionweaker-than-self-interest-based-arguments-why-taking.html

Calloway CG (2006) The scratch of a pen: 1763 and the transformation of North America. Oxford UP, Oxford

Carley M, Christie I (2001) Managing sustainable development. Earthscan, London 
Center for Responsive Politics (2010) James M Inhofe: campaign finance/money - summary senator 2010. Retrieved from http://www.opensecrets.org/politicians/summary.php? $\operatorname{cid}=\mathrm{N} 00005582$

Center for Responsive Politics (2010) Oil \& Gas. Retrieved from http://www.opensecrets.org/ industries/indus.php?ind=E01

Climate Analysis Indicators Tool (CAIT) (2010) Version 7.0. World Resources Institute, Washington, DC. Retrieved from http://cait.wri.org/

Cohen L (2003) Consumers' republic: the politics of mass consumption in postwar America. Vintage Books, New York

Cruz RV, Harasawa H, Lal M, Wu S, Anokhin Y, Punsalmaa B, Honda Y, Jafari M, Li C, Huu Ninh N (2007) Asia climate change 2007: impacts, adaptation and vulnerability. In: Parry ML, Canziani OF, Palutikof JP, van der Linden PJ, Hanson CE (eds) Contribution of Working Group II to the fourth assessment report of the Intergovernmental Panel on Climate Change, Cambridge University Press, Cambridge, pp 469-506. Retrieved from http://www.ipcc.ch/pdf/ assessment-report/ar4/wg2/ar4-wg2-chapter10.pdf

Cushman J (1998 April 26) Industrial group plans to battle climate treaty. New York Times, p 1

Dasgupta S, Laplante B, Meisner C, Wheeler D, Jianping Yan (2007) The impact of sea level rise on developing countries: a comparative analysis. World Bank Policy Research Working Paper 4136, February 2007. Retrieved from http://www-wds.worldbank.org/external/default/ WDSContentServer/IW3P/IB/2007/02/09/000016406_20070209161430/Rendered/PDF/ wps4136.pdf

Ford (2007) Are you tough enough? Commercial. Retrieved from http://www.youtube.com/ watch? $\mathrm{v}=\mathrm{iK}$-neU5OnsI

Foy P (2010, Feb 3) Utah Gov. Gary Herbert given $\$ 10 \mathrm{~K}$ by Alton coal development. Deseret News. Retrieved from http://www.deseretnews.com/article/print/700006916/Utah-Gov-GaryHerbert-given-10K-by-Alton-Coal-Development.html

Grabb E, Baer D, Curtis J (1999) The origins of American individualism: reconsidering the historical evidence. Can J Sociol 24(4):511-533

Harkinson J (2009 Jul 1) Despite pledge, ExxonMobil still funding climate change deniers. Mother Jones. Retrieved from http://motherjones.com/blue-marble/2009/07/despite-pledgeexxonmobil-still-funding-climate-change-deniers

Hulme M (2009) Why we disagree about climate change: understanding controversy, inaction and opportunity. Cambridge University Press, Cambridge

Jastrow R, Nierenberg W, Seitz F (1989) Global warming: what does the science tell us? George C. Marshall Institute, Washington, D.C

Larsen R (2010 Feb 6) Gore \& Co. Distorting facts. In Letters to the Editor. The Herald Journal. Retrieved from http://news.hjnews.com/opinion/letters_to_the_editor/article_1ea53ac8-ad805c99-a9db-fcd23e3f747e.html

Ngo Thi Phuong Lan (2010) From rice to shrimp: ecological change and human adaptation in the Mekong Delta. Paper given at the international conference on environmental change, agricultural sustainability, and economic development in the Mekong Delta of Vietnam, Can Tho University, Can Tho, 25-27 March 2010

Oreskes N, Conway EM (2010) Merchants of doubt: how a handful of scientists obscured the truth on issues from tobacco smoke to global warming. Bloomsbury Press, New York

Pickens T (2010) The Pickens Plan. Retrieved from www.pickensplan.com

Roberts SE (2010) Pines, profits, and popular politics: responses to the White Pine Acts in the colonial Connecticut River Valley. New Engl Quart 83(1):73-101

Schwartz M (2010) Firing line. The New York Times Magazine. 38-43, 1 Aug 2010

Shain B (1994) The myth of American individualism. Princeton University Press, Princeton

Shulman Seth (2006) Undermining science: suppression and distortion in the Bush administration. University of California Press, Berkeley

Thoreau HD $(1854,1981)$ Walden and other writings by Henry David Thoreau. Bantam, New York

Toyota (2010) Harmony commercial. Retrieved from http://www.youtube.com/watch?v= Tq4nrmnqY9o 
Union of Concerned Scientists (2007 Jan 3) Scientists' report documents ExxonMobil's tobaccolike disinformation campaign on global warming science. Retrieved from http://www.ucsusa. org/news/press_release/ExxonMobil-GlobalWarming-tobacco.html?print=t

United Nations Statistics Division (2010) Millennium development goals indicators. Retrieved from http://mdgs.un.org/unsd/mdg/SeriesDetail.aspx?srid=749\&crid=

US Department of Transportation. (2009) Consumer Assistance to Recycle and Save Act of 2009 Report to the House Committee on Energy and Commerce, the Senate Committee on Commerce, Science, and Transportation and the House and Senate Committees on Appropriations. Retrieved from http://www.cars.gov/files/official-information/CARS-Reportto-Congress.pdf

Utah State Legislature (2010 Feb 9) Climate change joint resolution. Retrieved from http://le.utah. gov/ 2010/bills/hbillamd/hjr012.htm

Vaughan A (2009 Sept 2) A history of $\mathrm{CO}_{2}$ emissions. Guardian.co.uk. Retrieved from http:// www.guardian.co.uk/environment/datablog/2009/sep/02/co2-emissions-historical

Vietnam News Service (2010 Jan 7) Imported rice brands dominate markets in the Mekong Delta. Viet Nam News. Retrieved from http://vietnamnews.vnanet.vn/Economy/195638/Importedrice-brands-dominate-markets-in-the-Mekong-Delta-.html 